\title{
A DIMENSÃO TRANSFRONTEIRIÇA NAS LIGAÇÕES INTERNACIONAIS ENTRE CIDADES: COMENTÁRIOS SOBRE UMA NOVA INFORMAÇÃO DA REGIC 2018 ${ }^{1,2}$
}

\author{
Rosa Moura ${ }^{3}$ \\ Gustavo Ferreira ${ }^{4}$ \\ Liria Nagamine ${ }^{5}$
}

\section{INTRODUÇÃO}

Com a publicização dos resultados da pesquisa Regióes de Influência das Cidades (Regic) 2018 (IBGE, 2020), que, desde os anos 1960, investiga periodicamente a classificação hierárquica dos centros urbanos e identifica suas respectivas regiôes de influência, as relaçôes internacionais entre municípios brasileiros ganharam maior visibilidade. Trata-se de um levantamento inédito na história da série Regic e seus resultados devem ser considerados um avanço na compreensão das ligaçôes da rede urbana além fronteira. Duas informaçôes foram obtidas nesse levantamento: a atratividade internacional das cidades brasileiras, medida pela capacidade de atração das cidades da faixa de fronteira terrestre - estabelecida pela Lei $\mathrm{n}^{\mathrm{o}}$ 6.634/1979 - a cidades dos países vizinhos; e a conectividade internacional das cidades brasileiras, avaliada pela presença e funcionamento em cidades brasileiras de firmas e serviços vinculados a redes empresariais de companhias com multilocalização em diversos países.

As primeiras são o objeto dos comentários aos quais se volta este texto, dada sua relevante contribuição ao projeto A Política Nacional de Desenvolvimento Regional (PNDR) e a Faixa de Fronteira, em desenvolvimento no Ipea, pois se constata completa aderência de seus resultados a dinâmicas evidenciadas nas unidades identificadas e sugeridas como arranjos transfronteiriços no âmbito desse projeto (Pêgo et al., 2021).

O texto se organiza em três partes, afora esta introdução, que objetivam: i) tecer comentários sobre as motivaçôes que impulsionam a atratividade internacional das cidades da faixa de fronteira, conforme a pesquisa do Instituto Brasileiro de Geografia e Estatística

1. DOl: http://dx.doi.org/10.38116/brua24art8.

2. Os autores agradecem à leitura atenta, aos comentários e às sugestões da parecerista Alessandra Ruffino, que possibilitaram ajustes fundamentais ao texto.

3. Profissional sênior na Diretoria de Estudos e Políticas Regionais, Urbanas e Ambientais (Dirur) do Ipea.

4. Pesquisador do Programa de Pesquisa para o Desenvolvimento Nacional (PNPD) na Dirur//pea.

5. Pesquisadora do PNPD na Dirur/lpea. 
(IBGE); ii) traçar observaçôes sobre a relevância das ligações internacionais na configuração de arranjos transfronteiriços e em sua importância na rede urbana brasileira; e iii) diante dos motivos que estreitam as ligaçôes entre os centros, apontar os elementos mais desafiadores na gestão desses espaços transfronteiriços.

\section{MOTIVAÇÕES À ATRATIVIDADE INTERNACIONAL DAS CIDADES DA FAIXA DE FRONTEIRA}

Na pesquisa Regic 2018 (IBGE, 2020), foi aplicado um questionário específico para identificar as ligaçóes internacionais entre cidades da faixa de fronteira terrestre, com a finalidade de identificar as origens e destinos; os motivos e os graus de atratividade dessas cidades. O questionário foi aplicado a responsáveis pelas agências do IBGE, cujo conhecimento empírico trouxe resposta à indagação: "De quais cidades dos países vizinhos são oriundas as pessoas que vêm adquirir bens e serviços no Brasil?" (IBGE, 2020, p. 147). Movimentos no sentido oposto, do Brasil para cidades dos países vizinhos, também ocorrem, porém não foram contemplados por essa pesquisa.

Os resultados dessa pesquisa permitem observar que a influência de uma cidade, ao fornecer bens e serviços, é proporcional à distância a partir das fronteiras, reduzindo o número de localidades que a ela se relacionam na medida em que se afasta da fronteira. A quantidade dos relacionamentos guarda proporcionalidade à densidade de cada porção fronteiriça, com padrôes mais complexos nas fronteiras do arco Sul que nos arcos Central e Norte.

Paraguai e Argentina são os países com os maiores números de cidades (68 e 57, respectivamente) que realizam ligaçóes com cidades brasileiras, conforme mostra a tabela 1 . Vêm seguidos por Uruguai e Bolívia. Rio Grande do Sul é o estado com o número mais elevado de cidades com atratividade internacional na faixa de fronteira (89 cidades). Paraná e Mato Grosso do Sul vêm na sequência, com respectivamente 50 e 35 cidades.

TABELA 1

Países e número de cidades de origem e Unidades da Federação (UFs) e número de cidades de destino das ligações internacionais

\begin{tabular}{lclc}
\hline País de origem & Número de cidades & UF de destino no Brasil & Número de cidades \\
\hline Paraguai & 68 & Rio Grande do Sul & 89 \\
Argentina & 57 & Paraná & 50 \\
Uruguai & 38 & Mato Grosso do Sul & 35 \\
Bolívia & 26 & Amazonas & 10 \\
Peru & 12 & Rondônia & 10 \\
Venezuela & 9 & Acre & 9 \\
Colômbia & 8 & Roraima & 9 \\
Equador & 3 & Santa Catarina & 8 \\
Guiana & 3 & Mato Grosso & 4 \\
Guiana Francesa & 1 & Amapá & 1 \\
Suriname & 1 & Pará & 1 \\
Total & $\mathbf{2 2 6}$ & Total & $\mathbf{2 2 6}$ \\
\hline \multicolumn{1}{c}{ Fonte: IBGE (2020). } & & &
\end{tabular}

Das ligaçóes internacionais computadas, 15 podem ser consideradas de longa distância e 211 descrevem fluxos de curta distância. Somadas, apontam para 226 ligaçóes internacionais. Os fluxos direcionados a cidades da faixa de fronteira representam majoritariamente 
contatos de curta distância, como mostra o mapa 1. Os fluxos de longa distância, nem sempre destinados a cidades da linha de fronteira, registram uma única finalidade no destino, constatadas em três motivaçóes: i) busca por ensino superior, nas ligaçóes entre Bogotá, Caracas, Lima e Quito com os municípios Capão do Leão e Pelotas (Rio Grande do Sul), entre Lima e Rio Grande (Rio Grande do Sul) e entre Tacna (Peru) e Sant'Ana do Livramento (Rio Grande do Sul); ii) atividades esportivas, nos fluxos entre Lima, Quito e Santa Cruz de la Sierra, com Alegrete (Rio Grande do Sul) e entre Medellín (Colômbia) e Chapecó (Santa Catarina); e iii) atividades culturais, unicamente na ligação entre Buenos Aires e Corumbá (Mato Grosso do Sul).

\section{MAPA 1}

América do Sul: ligações internacionais com destino a municípios da faixa de fronteira terrestre (2018)

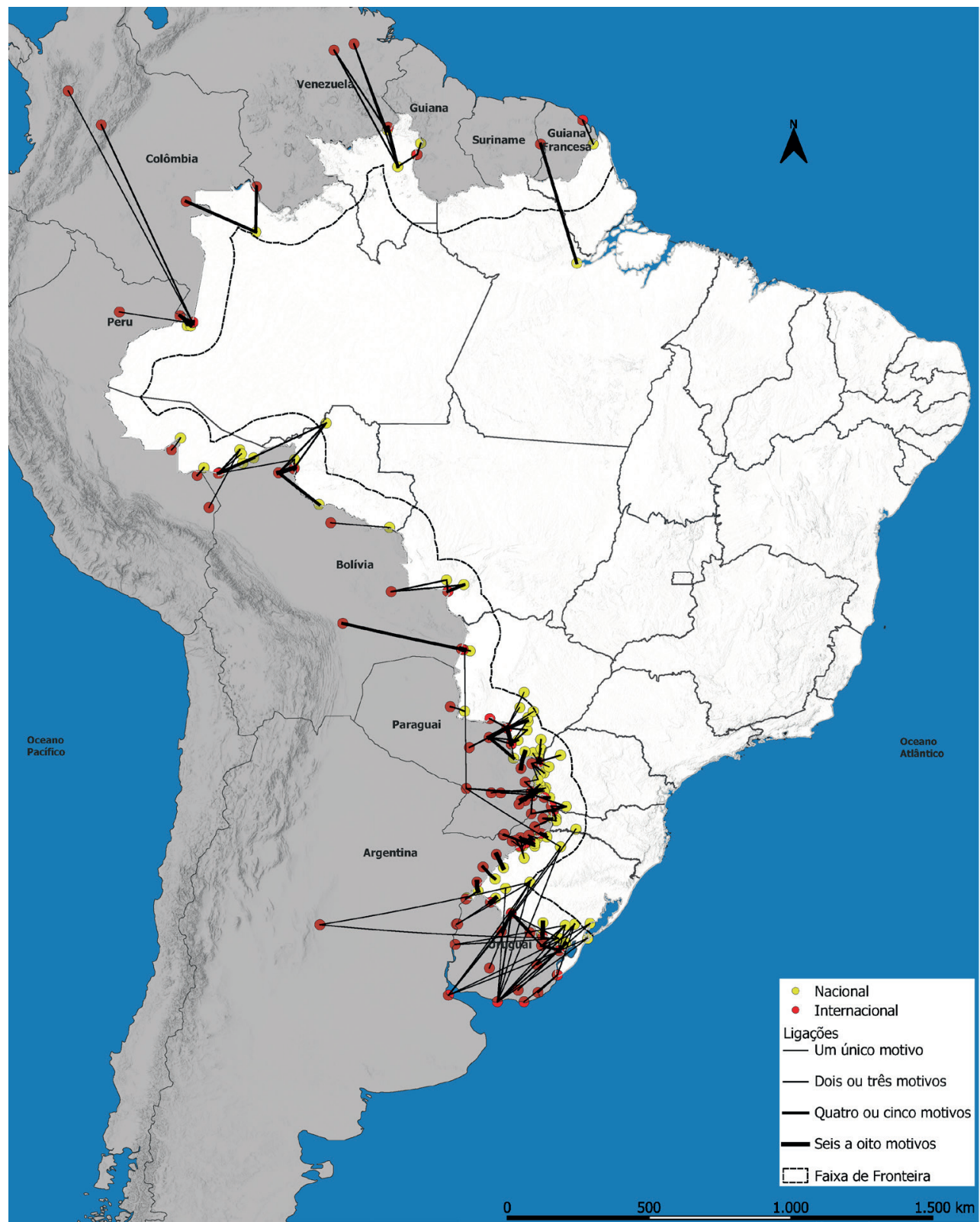

Fonte: IBGE (2020)

Elaboração da Equipe Fronteiras//pea.

Obs.: 1. Não foram mapeadas as ligações de longa distância entre: Bogotá-Capão do Leão, Pelotas; Buenos Aires-Corumbá; Caracas-Capão do Leão, Pelotas; Lima-Alegrete, Capão do Leão, Pelotas, Rio Grande; Medellín-Chapecó; Quito-Alegrete, Capão do Leão, Pelotas; Santa Cruz de la Sierra-Alegrete; Tacna-Santana do Livramento.

2. Figura cujos leiaute e textos não puderam ser padronizados e revisados em virtude das condições técnicas dos originais (nota do Editorial). 
Segundo o IBGE (2020, p. 148), no caso da primeira motivação, os deslocamentos para Capão do Leão e Pelotas, ambas no Rio Grande do Sul, ocorrem em virtude "dos campi da Universidade Federal de Pelotas (Ufpel) realizarem convênios com bolsas de graduação e pós-graduação destinados a alunos de países sul-americanos. No caso específico da Venezuela, há bolsas voltadas para refugiados". A atratividade de Alegrete para esportes se deve a um torneio internacional anual infantil de futebol, considerado um dos maiores eventos do tipo na América Latina, e que é realizado há mais de trinta anos. No caso de Chapecó, existem as partidas internacionais.

Das 226 ligaçóes internacionais, 75 ocorreram por uma única motivação, 83 por dois ou três motivos, 30 por quatro a cinco motivos e 23 por seis a oito motivos. Este último conjunto expressa uma forte inteiração transfronteiriça entre cidades localizadas na linha de fronteira ou, quando não, por estarem integradas a algum arranjo transfronteiriço, como Bagé e o arranjo transfronteiriço de Aceguá (Rio Grande do Sul)-Acegua (Uruguai); e Mundo Novo (Mato Grosso), ao de Guaíra (Paraná)-Salto del Guairá (Paraguai).

Tendo em consideração os 563 fluxos detectados nas 226 ligaçóes entre cidades brasileiras e cidades dos países vizinhos, sejam de curta ou longa distância, constata-se que as atividades culturais são as principais motivaçóes, estando presente em 125 fluxos, ou $22,2 \%$ do total dos fluxos. Além de atividades rotineiras de proximidade, comuns nos arranjos transfronteiriços, em cidades mais distantes da linha de fronteira a atratividade se dá pela realização de festivais e eventos.

O segundo motivo mais referenciado é compra de vestuário ou calçados, motivo de 115 fluxos (20,4\%), e o terceiro, a busca por serviços de saúde de baixa e média complexidade, em 86 fluxos (15,3\%). Neste caso, a assimetria entre as cidades dos dois lados da fronteira na oferta desse serviço torna algumas cidades brasileiras atrativas, mas há casos em que são brasileiros que recorrem a esse tipo de serviço no país vizinho, particularmente na fronteira com o Uruguai. Outra motivação é a oferta pública universalizada no Brasil, enquanto nos países vizinhos a atenção primária se encontra privatizada.

Analisando a origem, Paraguai e Argentina registram o maior número de fluxos de ligação entre as cidades, respectivamente 177 e 143, e ambos são movidos pelas principais motivaçóes consideradas na pesquisa. No caso do Paraguai, com maior peso em relação às atividades culturais (45 registros) e serviços de saúde de baixa e média complexidade (31); no da Argentina, em compra de vestuário e calçados (41), compra de móveis e eletroeletrônicos (28) e atividades culturais (27). Uruguai, Bolívia e Colômbia também atendem às oito motivaçóes de buscas: no Uruguai, predominam atividades culturais e compras tanto de vestuário e calçados quanto de móveis e eletrodomésticos; na Bolívia, repetem-se nessas compras e acrescentam-se os serviços de saúde de baixa e média complexidade; e na Colômbia, com menor número total de fluxos (20), recaem sobre compras de vestuário e calçados e busca de ensino superior. Os demais países possuem números menores de fluxos e motivaçóes específicas, mas mesmo assim, os limítrofes apresentam um leque maior de motivaçóes.

Em se tratando das UFs, Rio Grande do Sul, Paraná, Mato Grosso do Sul, com mais de 100 registros de fluxos, e Amazonas, com apenas 32, exercem atratividade pelas oito motivaçôes para as ligaçóes internacionais entre cidades. As três primeiras UFs têm nas atividades culturais a principal motivação; a segunda motivação no Rio Grande do Sul e do Mato Grosso do Sul são as compras de vestuário e calçados; no Paraná e também no Mato Grosso do Sul, a busca por serviços de saúde de baixa e média complexidade. No Amazonas, 
a principal motivação são as compras de vestuário e calçados, seguida por serviços de saúde de baixa e média complexidade. Observa-se que essas três motivaçôes estão presentes na atratividade das cidades em todas as UFs da faixa de fronteira.

Os destinos com o maior número de cidades de origem das ligaçóes internacionais e o maior elenco de motivos para deslocamentos vindos do estrangeiro correspondem a arranjos populacionais (APs) internacionais e respeitam a seguinte ordem de grandeza: i) maior número de municípios de origem e de motivos: Foz do Iguaçu (Paraná) e Ponta Porã (Mato Grosso do Sul); ii) elevado número de motivaçóes e procura por mais de uma cidade: Corumbá (Mato Grosso do Sul) e Guajará-Mirim (Roraima); e iii) elevado número de motivaçôes, porém procurada por uma única cidade: Tabatinga (Amazonas), Mundo Novo e Sete Quedas (Mato Grosso do Sul), Bagé, Jaguarão, Quaraí, Santana do Livramento, São Borja e Uruguaiana (Rio Grande do Sul), Guaíra e Barracão (Paraná) e Dionísio Cerqueira (Santa Catarina) - estes últimos, integrantes do mesmo AP internacional.

Em termos de padrão, observa-se uma complexidade decorrente de múltiplas ligaçôes entre cidades na porção fronteiriça do Paraná com Paraguai e Argentina, o que sugere, conforme IBGE (2020, p. 147) "uma interpenetração econômica da área para além do conhecido polo comercial Foz do Iguaçu (PR)-Ciudad del Este (Paraguai)". Também há maior penetração no território de ambos os países nas ligaçôes de cidades do Rio Grande do Sul com cidades da Argentina e Uruguai.

Em termos de dificuldade de acesso, a ligação entre a localidade de Cottica (Suriname) e o AP Laranjal do Jari (Amapá)-Almeirim (Pará) é explicada pelo IBGE (2020, p. 147) como devida a que os deslocamentos "não se dão entre sedes urbanas, mas entre aldeias indígenas situadas nos dois países. Trata-se de um movimento esporádico realizado, exclusivamente, por via aérea e, eventualmente, preenchendo diversos temas, como compras de vestuário e calçados, saúde, lazer, entre outros." Também São Gabriel da Cachoeira (Amazonas) se vale da dificuldade de acesso de cidades fronteiriças da Colômbia e Venezuela com as centralidades dos respectivos países. "A cidade brasileira passa a funcionar como a única referência de centralidade de fato dada a convergência da rede fluvial, que é usada como meio de transporte por aquelas populaçóes" (IBGE, 2020, p. 148).

Cabe salientar, para além das motivaçóes avaliadas pela pesquisa Regic de 2018 (IBGE, 2020), que outras, sintetizadas na sequência, foram relatadas por participantes fronteiriços nas atividades desenvolvidas nos arcos Norte, Central e Sul, no projeto em curso e nas visitas aos arranjos transfronteiriços realizadas pela equipe Ipea (Pêgo et al., 2021). A essas se somam outras que resultaram da pesquisa de campo realizada no âmbito do projeto do Ministério da Justiça e Cidadania: Municípios de Fronteira: mobilidade transfronteiriça, migração, vulnerabilidades e inserção laboral (Brasil, 2016b). Em ambos os casos referem-se a ligaçóes nos dois sentidos entre os países.

Duas motivaçôes urbanas e rurais fazem o amálgama da interação nas áreas transfronteiriças. Uma dessas, generalizada aos três arcos, são os fluxos que se ativam nas relaçôes familiares, em laços de parentesco, compadrios e amizades que desconhecem fronteiras - elas induzem trocas culturais e a manifestação de uma interculturalidade que enriquece as relaçóes sociais e motivam deslocamentos internos aos arranjos para a vivência do cotidiano. Outra motivação se expressa na mobilidade intensa de povos indígenas, particularmente nos arcos Norte e Central, e sua busca, nas áreas urbanas, por serviços de saúde e assistência social, mas também para atividades informais e mendicância. Entretanto, um ir e vir cotidiano 
ou esporádico adquire especificidades em cada arco fronteiriço, e no próprio interior deles, pois têm relaçóes diretas com a natureza das interaçóes que se dão com cada país vizinho.

No arco Norte, de modo geral, se trata de um movimento informal que alimenta o mercado de trabalho em atividades extrativas ou tipicamente urbanas; são peculiares ao arco os deslocamentos para atividades no garimpo, particularmente entre municípios brasileiros e Guiana Francesa, Suriname e Venezuela. Com este país, a compra de combustível já foi uma das principais motivaçóes de busca por brasileiros.

No arco Central também se destacam os fluxos de pessoas para trabalho em atividades urbanas e rurais, a maioria por trabalhadores informais, pouco especializados, que cruzam a fronteira do Brasil em direção à Bolívia ou ao Paraguai e vice-versa, assim como os fluxos para estudo, nos ensinos fundamental e médio, nas escolas urbanas e rurais, localizadas próximas à fronteira, e educação superior, fundamentalmente cursos de medicina, em cidades da Bolívia e do Paraguai. Também são comuns fluxos para a busca de serviços públicos no Brasil, particularmente saúde, dada a não universalização da saúde pública nos países vizinhos e, no sentido inverso, a procura por brasileiros pelo comércio de importados nos países vizinhos. Uma peculiaridade na movimentação transfronteiriça na fronteira com Bolívia é a predominância de bolivianos na produção para comercialização de hortigranjeiros nas cidades fronteiriças brasileiras.

Além das motivaçôes para trabalho, consumo e uso de serviços públicos, que se repetem nos três arcos, no arco Sul, há um movimento muito intenso gerado pela atividade turística, particularmente no caso do Parque Nacional do Iguaçu, visitado dos lados brasileiro e argentino, que se associa ao turismo de compras de produtos importados nos grandes centros comerciais e comércio de rua, majoritariamente em Ciudad del Este. O turismo de compras também é um forte atrativo em Pedro Juan Caballero e outras cidades do Paraguai, assim como em lojas francas do Uruguai. A indústria do turismo emprega, nas atividades do secundário e terciário, formal e informalmente, moradores dos dois ou três lados da fronteira, que circulam cotidianamente no interior dos arranjos, e trabalham como lojistas, atendentes, ambulantes, trabalhadores da construção civil, serviços domésticos, entre outros. No caso da fronteira com o Uruguai, a busca por serviços públicos de saúde e educação também ocorre na direção inversa, muitas vezes justificada pela menor distância ou maior facilidade de acesso a cidades do país vizinho. Há que salientar que a maioria dos arranjos transfronteiriços na fronteira com a Argentina sofre com as dificuldades da travessia por balsas.

Outra motivação de deslocamentos de brasileiros registrada nos três arcos da fronteira é a frequência a bares, casas noturnas, restaurantes, casas de jogos, entre outras diversóes nas cidades "do lado de lä" das fronteiras. Associa-se a ela o movimento de ilícitos, como tráfico de drogas e de pessoas, particularmente mulheres, crianças e outros segmentos vulneráveis, como indígenas, para a prostituição ou para servirem de "mulas" no tráfico de drogas.

Por fim, cabe destaque aos movimentos pendulares para trabalho e/ou estudo em países estrangeiros, cujas informaçōes, disponibilizadas pelo IBGE no censo demográfico de 2010, oferecem importantes subsídios para análises de fluxos de municípios brasileiros com destino a outros países (nesse caso não foram pesquisados os que ocorrem na direção inversa, de estrangeiros com destino aos municípios brasileiros). ${ }^{6}$

6. Análises específicas sobre o tema constam em estudos que integram o projeto em desenvolvimento no Ipea (Cardoso e Moura, 2017; Deschamps, Delgado e Moura, 2018). 
O resultado dessas pesquisas confirma que há uma dimensão transfronteiriça que perpassa a linha de fronteira terrestre, assumindo maior relevância nos arranjos espaciais bi ou trinacionais. Uma dimensão que assimila a diversidade de seus povos e impulsiona uma intensa e contínua mobilidade transfronteiriça, pendular, de passagem ou migratória, que amplia a multidimensionalidade cultural, econômica e social, a maioria estabelecida na esfera do informal, e impóe açóes que garantam preservar identidades e fortalecer a interculturalidade. Tal diversidade por vezes acelera processos que exigem reflexão apurada e açóes emergenciais.

\section{A ATRATIVIDADE INTERNACIONAL DOS ARRANJOS TRANSFRONTEIRIÇOS}

As informaçôes sobre a atratividade internacional das cidades brasileiras, disponibilizadas pela Regic 2018, encontraram completa consonância às configuraçôes espaciais que no projeto citado são consideradas arranjos transfronteiriços. Tratam-se de espaços de ocupação contínua ou de forte conexão entre cidades de países vizinhos em uma zona onde convivem diferentes povos e culturas, por onde perpassam fluxos de interaçáo cotidianos e se realizam atividades comuns aos países fronteiriços; uma zona híbrida, na qual se mesclam identidades originais e se constrói uma nova identidade (Moura e Oliveira, 2018). ${ }^{7}$ São arranjos resultantes de uma configuração polidimensional, ou seja, tanto referente à dimensão gerada pela aglomeração, cidade ou povoado de cada lado da fronteira, quanto à dimensão que se constitui a partir de uma simbiose nas interaçóes cotidianas entre essas, prescindindo a linha de fronteira. E se confirmam na compreensão do IBGE (2020, p. 147) de que a "hinterlândia das Cidades brasileiras avança sobre o território dos demais países, sendo referência tanto de cidadáos estrangeiros quanto de brasileiros residentes no exterior para a aquisiçáo de produtos e o usufruto de serviços".

No âmbito do projeto em desenvolvimento pelo Ipea, foram identificados 32 arranjos transfronteiriços, integrados por 39 municípios brasileiros e 41 dos países vizinhos, somando 80 unidades político-administrativas locais (Pêgo et al., 2021). Alguns desses arranjos integram o elenco das cidades gêmeas, dispostas pelo Ministério do Desenvolvimento Regional (MDR) (Brasil, 2016a; 2019); outros, os arranjos populacionais internacionais, conforme IBGE (2020).

Distribuem-se entre os três arcos da fronteira terrestre: sete arranjos no arco Norte, sendo dois trifronteiriços (Brasil, Colômbia e Peru; e Brasil, Peru e Bolívia); oito arranjos no arco Central, um deles compartilhado com o arco Sul (Mato Grosso do Sul, Paraná e Paraguai); e 17 arranjos no arco Sul, sendo dois compartilhados entre estados (o já citado e outro entre Paraná, Santa Catarina e Argentina) e dois arranjos em fronteira tríplice (Brasil, Paraguai e Argentina; e Brasil, Argentina e Uruguai), conforme mostra o mapa 2. Outros arranjos se conformam na linha de fronteira terrestre, demandantes de estudos específicos e mais detalhados para sua delimitação, mas já detectadas as ligações internacionais com municípios dos países vizinhos na Regic 2018. Outros municípios da linha de fronteira, sem continuidade/contiguidade de ocupação observadas, também se confirmam ligaçôes com municípios e povoados de países vizinhos.

7. As publicações resultantes do projeto em desenvolvimento pelo Ipea (Pêgo e Moura, 2018; Pêgo et al., no prelo), tomado como base para se tecer os comentários propostos neste texto, trazem discussões teórico-conceituais sobre relações interfronteiriças e transfronteiriças, conceitos sobre várias dimensões sociais e geográficas das fronteiras, entre outros temas. 
MAPA 2

Brasil: arranjos transfronteiriços (2019)

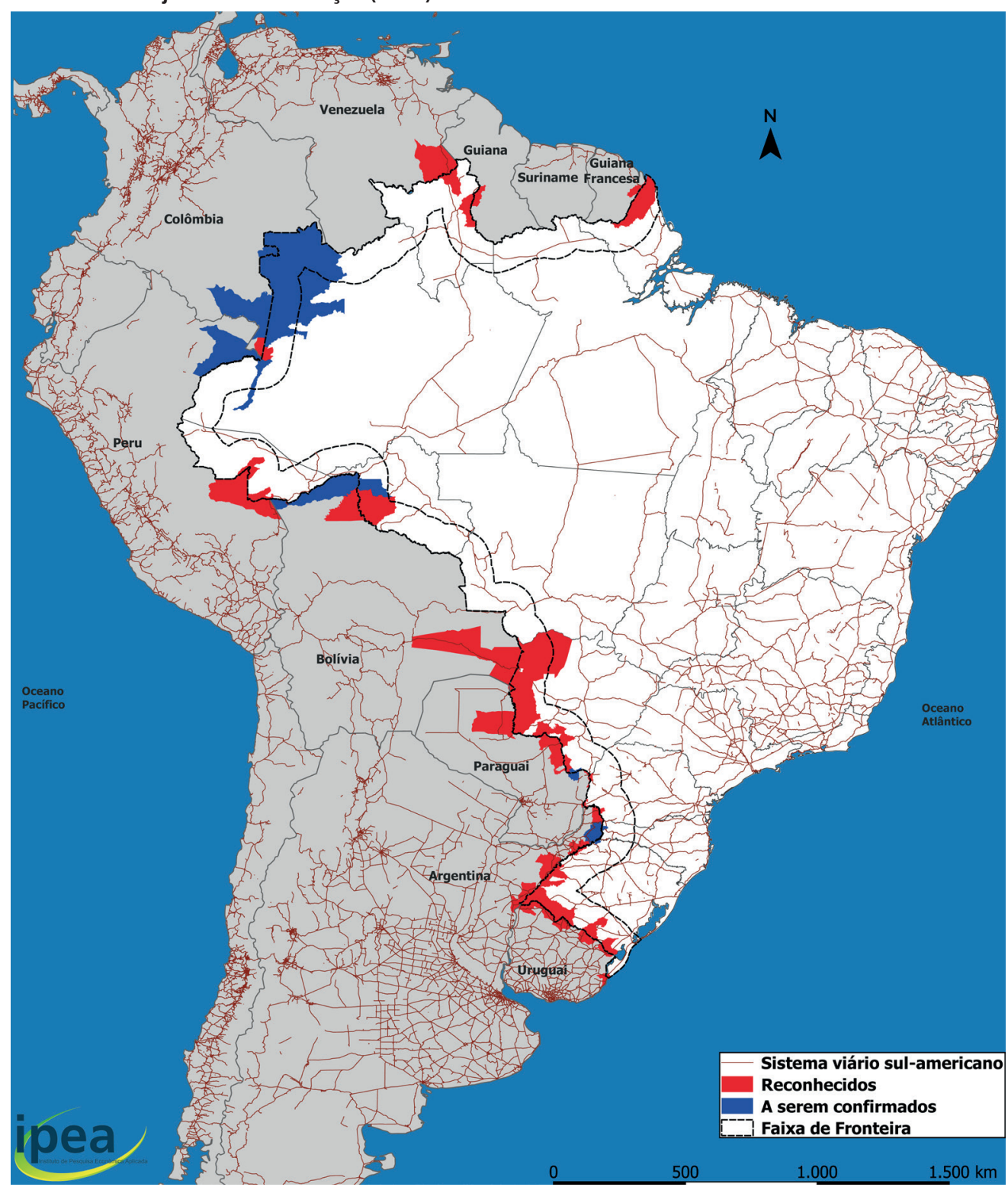

Fonte: Pêgo et al. (2021); DNIT, 2018

Elaboração da Equipe Fronteiras//pea.

Obs.: Figura cujos leiaute e textos não puderam ser padronizados e revisados em virtude das condições técnicas dos originais (nota do Editorial).

Chama-se a atenção para o fato de que muitos desses possíveis arranjos ou cidades com ligaçóes internacionais confirmadas, nos arcos Norte e Central, têm na dimensão transfronteiriça relaçôes entre indígenas dos distintos países, não se configurando como unidades derivadas da ocupação urbana. Da mesma forma, as relações de trabalho em atividades do setor primário, que consolidam relaçôes transfronteiriças nesses mesmos arcos, provocam similar simbiose em toda a unidade municipal.

A configuração de arranjos espaciais é uma tendência da urbanização nas regióes de fronteiras, pela intensa comutação e interação entre os povos e pela sinergia impulsionada na oscilação de oportunidades econômicas e cambiais entre os países, que gera a dimensão transfronteiriça, indo além da escala local de cada cidade. Eles sintetizam os mais elevados graus de urbanização; predominância de ocupação em atividades não agrícolas; desenvolvimento de 
fluxos pendulares - nesse caso entre municípios de diferentes países, para trabalho, estudo, consumo de bens e acesso a serviços -; e manchas contínuas de ocupação, sobre as quais a linha de fronteira tem completa porosidade, viabilizando as interaçóes e a mobilidade transfronteiriça, desempenhando importante papel de intermediação nas redes urbanas dos distintos países. Constituem mosaicos urbanos complexos, que devem ser compreendidos em sua totalidade, mas ainda pouco reconhecidos e priorizados na agenda governamental, portanto carentes de políticas públicas adequadas às suas demandas e ao seu papel na rede de cidades.

Os resultados da pesquisa Regic 2018 tornam evidente a qualificação das cidades que integram arranjos transfronteiriços, dada a elevaçáo do nível de seu posicionamento na hierarquia urbana brasileira. A principal elevação de nível foi constatada em relação ao arranjo populacional internacional (AP) ${ }^{8}$ de Foz do Iguaçu (Paraná)-Ciudad del Este (Paraguai), que agrega um número maior de municípios que os considerados pelo IBGE, tanto do Brasil, quanto do Paraguai, além de Puerto Iguazú (Argentina). Esse AP internacional teve sua classificação elevada de centro sub-regional para capital regional. Outros APs internacionais elevaram a classificação de centros de zona para centros sub-regionais, casos de Brasileia/Epitaciolândia (Acre)-Cobija (Bolívia); Guajará-Mirim (Roraima)-Guayaramerín (Bolívia); Corumbá/Ladário (Mato Grosso do Sul)-Puerto Quijarro/Puerto Suárez (Bolívia); Ponta Porã (Mato Grosso do Sul)-Pedro Juan Caballero/Zanja Pytá (Paraguai); Guaíra (Paraná)-Mundo Novo (Mato Grosso do Sul)-Salto del Guairá (Paraguai); Sant'Ana do Livramento (Rio Grande do Sul)-Rivera (Uruguai); e São Borja (Rio Grande do Sul)-Santo Tomé (Argentina), além de Tabatinga (Amazonas)-Leticia (Colômbia)-Santa Rosa (Peru). Entre os arranjos transfronteiriços, apenas Cáceres (Mato Grosso)-San Matías (Bolívia) teve queda dentro do próprio nível de classificação, passando de centro sub-regional A para B.

De modo geral, os municípios da faixa de fronteira e suas centralidades mais expressivas demonstram pequena articulação à rede urbana brasileira, sendo que o mesmo ocorre em relação aos municípios fronteiriços e às redes de cidades dos respectivos países. Distância das centralidades principais e meios de comunicação e acessibilidade precários são os principais limitantes das conexôes entre os centros, particularmente nos arcos Norte e Central (Pêgo et al., 2021). Essas condiçôes de precariedade atribuem um papel de redobrada importância aos arranjos transfronteiriços, como centralidades com influência regional sobre municípios dos países vizinhos, pois muitas vezes as dificuldades de conexão e as distâncias são maiores em relação aos centros principais dos respectivos países.

No arco Sul, as cidades da faixa de fronteira guardam maior proximidade às principais centralidades da rede urbana brasileira e possuem vias de ligação com centralidades dos países vizinhos em melhores condiçôes que nos demais arcos (mapa 3). Mesmo assim, há cidades na fronteira do Rio Grande do Sul com mais facilidade de acesso a centralidades dos países vizinhos que às brasileiras (Pêgo et al., 2021). Particularmente no arco Norte, há localidades sem acesso pelo sistema rodoviário, a exemplo do arranjo transfronteiriço Tabatinga (Amazonas)-Letícia (Colômbia)-Santa Rosa (Peru), no qual o acesso é por via aérea ou fluvial. Ainda assim, vale apontar que o aeroporto na regiáo não opera voos internacionais.

8. Para o IBGE (2020, p. 11), a unidade urbana de análise e exposição dos resultados dessa pesquisa trata-se de município e AP - este considerando o "fato de que a unidade funcional Cidade, objeto do atual estudo, pode vir a ser composta não apenas por um, mas por vários Municípios que são indissociáveis como unidade urbana. Trata-se de Municípios conurbados ou que possuem forte movimento pendular para estudo e trabalho, com tamanha integração que justifica considerá-los como um único nó da rede urbana". 
MAPA 3

Brasil: hierarquia e rede de relações dos centros urbanos da faixa de fronteira (2018)

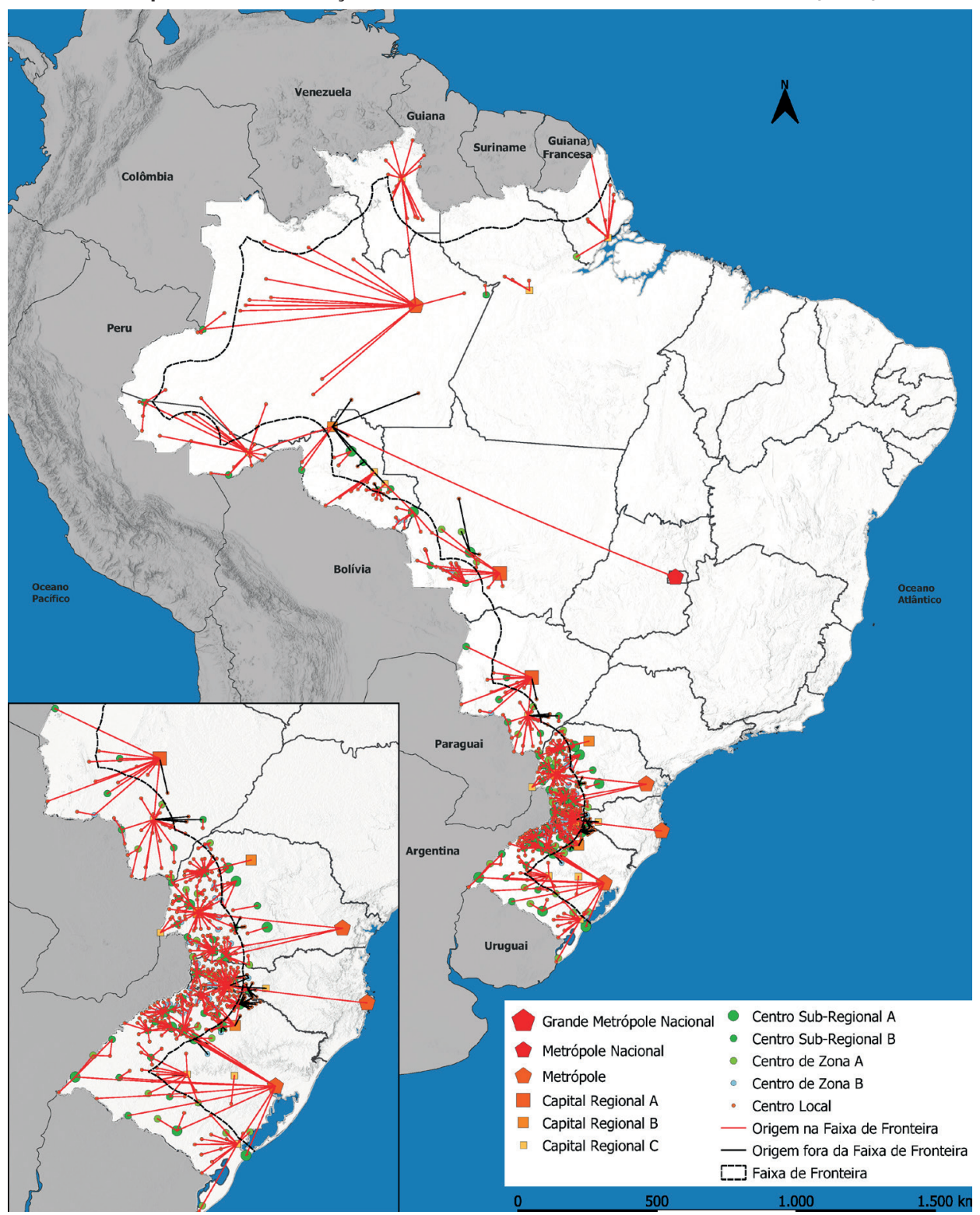

Fonte: IBGE (2020)

Elaboração da Equipe Fronteiras/lpea.

Obs.: 1. Foram mapeadas as cidades de origem que integram a faixa de fronteira, e separadas apenas as ligações com vínculos à rede urbana (resposta "sim"); das que não integram a faixa de fronteira, foram identificados os destinos dentro da faixa e mapeados os vínculos (resposta "sim"). Ou seja, examinou-se a faixa de fronteira sob a perspectiva de quem procura e de quem é procurado, mesmo que por cidades de fora dela. 2. Figura cujos leiaute e textos não puderam ser padronizados e revisados em virtude das condições técnicas dos originais (nota do Editorial).

Segundo a Regic 2018, são poucos os municípios da faixa de fronteira classificados nos patamares superiores da hierarquia de centros, não ocorrendo classificação na condição de metrópole ou capital regional A. Classificados como capitais regionais $\mathrm{B}$, encontram-se os APs de Porto Velho (capital de Rondônia), no arco Central; e Cascavel (Paraná) e Chapecó (Santa Catarina), no arco Sul. Como capitais regionais C, as capitais estaduais Rio Branco (Acre) e Boa Vista (Roraima), no arco Norte, assim como Dourados (Mato Grosso do Sul), no arco Central, e os APs de Pelotas (Rio Grande do Sul) e Foz do Iguaçu (Paraná) no arco Sul. Dois destaques são necessários: i) todos os centros classificados como capitais regionais no arco Norte são capitais de Unidades da Federação (UFs), cuja posição reforça a faixa de fronteira nesse arco, como também de Porto Velho, no arco Central; e ii) a configuraçáo 
espacial de arranjos populacionais, comum em regiôes adensadas, passa a pontuar também os municípios mais urbanizados dos arcos Norte e Central.

Há uma categoria que participa do exercício das relaçóes transfronteiriças que merece futura reflexão: a de cidade "conectora" (Egler, 2015). Ela se refere a centralidades da faixa de fronteira, como algumas capitais regionais, e também outras, situadas fora da faixa de fronteira, casos de Manaus e Cuiabá, que funcionam como conectoras na integração e na interaçáo transfronteiriça, articulando atividades econômicas e socioculturais, tornando-se destinos iniciais de trajetórias longas de migraçóes internacionais, entre outras.

\section{ALGUNS DESAFIOS PARA A GESTÃO}

Pela unidade espacial configurada, os arranjos transfronteiriços exigem políticas públicas adequadas às suas especificidades e que contemplem o grande número de funçóes públicas de interesse comum entre municípios de diferentes naçôes. O mesmo exigem as pequenas cidades ou povoados da linha de fronteira, que igualmente funcionam como portais para essa mobilidade. Ambos padecem de muitos males em comum à espera de políticas públicas mais efetivas.

Entre destaques dos participantes das atividades e estudos considerados no projeto que serve de parâmetro a esta análise constam: i) a urgência de medidas que assegurem o livre trânsito das pessoas residentes, com transporte urbano de passageiros que garanta a conectividade cotidiana; ii) a gestáo oficialmente compartilhada da prestação dos serviços de saúde, educação e assistência social, particularmente aos segmentos mais vulneráveis da população; iii) a oferta de moradia; iv) o acesso e a participaçáo em atividades culturais e esportivas; v) a garantia da documentação para o trabalho e usufruto dos direitos sociais; vi) o saneamento básico e a gestão ambiental, posto que a demarcação de fronteira não tem poder de influir em processos naturais; vii) a compatibilização das legislaçôes municipais e a convergência entre planos diretores urbanos e regulação urbanística; viii) a implementaçáo da governança compartida com a adequação da legislação de cooperação transfronteiriça; entre outros.

Além desses, o grande desafio no interior dos espaços transfronteiriços é a gestão do controle da fronteira, a partir de uma nova compreensão de seu significado, não mais como um elemento que separa, mas que une. A pandemia do novo coronavírus deixou evidente que o súbito fechamento das fronteiras terrestres, por meses, separou famílias e bloqueou relações cotidianas vitais, como acesso à saúde e ao trabalho. Para evitar tais situaçôes, qualquer controle fronteiriço deveria se dar no exterior da unidade urbana constituída, em um raio a ser definido a partir de sua centralidade. Arranjos transfronteiriços requerem ser compreendidos como uma unidade, e seus moradores, como cidadáos de um mesmo espaço, cuja gestão deve resultar de acordos e práticas bi ou trinacionais. Faz-se urgente, portanto, que a natureza das relaçóes transfronteiriças seja assimilada e difundida, e que as políticas para fronteira incorporem a dinâmica real desses espaços, em sua diversidade e distintos graus de complexidade morfológica e social, respeitando a especificidade de seus moradores e assumindo a existência de uma nova cidadania: a dos povos transfronteiriços.

\section{CONSIDERAÇÕES FINAIS}

Mais uma vez o IBGE disponibiliza uma importante contribuição à pesquisa sobre as relações entre as cidades brasileiras, inovando, desta feita, com a abordagem também sobre as ligaçôes internacionais entre centros. A leitura dos resultados dessa nova fonte de dados, à luz dos estudos do projeto A Política Nacional de Desenvolvimento Regional (PNDR) e a Faixa de Fronteira, em desenvolvimento no Ipea, demonstrou completa aderência à realidade fronteiriça. 
Aderência que se expressa: i) na ampliação da hinterlândia de cidades brasileiras sobre espaços dos países vizinhos; ii) na especificação dos motivos que impulsionam a atratividade dessas cidades; iii) na confirmação daqueles que promovem a interação cotidiana e instauram uma dimensão transfronteiriça nesses espaços; e iv) no reforço que essa atratividade desencadeia no leque funcional de arranjos transfronteiriços, posto que muitos obtiveram reposicionamento ascendente na escala da hierarquia urbana brasileira na pesquisa Regic de 2018.

Para o projeto do Ipea, as informaçóes contribuíram, de imediato, para salientar a importância em se aprofundar o estudo, voltando-se a configuraçôes transfronteiriças ainda não elencadas entre as cidades-gêmeas, do MDR, ou os arranjos populacionais internacionais, do IBGE. Esse aprofundamento já faz parte das propostas da etapa que se inicia no projeto e que, certamente, vai se valer muito dos dados disponibilizados. Apenas se ressente que o levantamento da atratividade internacional ainda não contemple a direção oposta, no sentido das cidades brasileiras para cidades dos países vizinhos, dada a impossibilidade de formas diretas de captá-los, como justifica o IBGE.

Quanto aos arranjos populacionais internacionais, a base de dados que agrega os produtos integrantes da Regic 2018 ofereceu uma atualização dos municípios componentes nesses arranjos. Confirmou-se também que todos já estavam considerados no projeto do Ipea como arranjos transfronteiriços. Porém, nessa relação sente-se falta de alguns importantes, já relacionados entre as cidades-gêmeas, que, embora não configurem manchas de ocupação urbana em contiguidade ou continuidade, realizam uma forte interação pela conectividade motivada pelos mesmos serviços e atividades medidos no levantamento de atratividades. Casos, por exemplo, de Pacaraima (Roraima)-Santa Elena de Uairén (Venezuela)-Cáceres (Mato Grosso)-San Matías (Bolívia), entre outros.

Essas duas breves lacunas absolutamente não comprometem a importância das informaçôes analisadas nesses comentários. Outra vez, parabeniza-se o IBGE pela longevidade, sistematicidade e aprimoramentos contínuos à pesquisa Regic, e se agradece pela publicização do acesso a informaçôes que contam a história da rede urbana brasileira e permitem que se ensaie tendências sobre seus rumos futuros.

\section{REFERÊNCIAS}

BRASIL. Ministério da Integração Nacional. Portaria no 213 de 19 de julho de 2016. Estabelece o conceito de "cidades-gêmeas" nacionais, os critérios adotados para essa definição e lista todas as cidades brasileiras por estado que se enquadram nesta condição. Diário Oficial da Uniáo, Brasília, 20 jul. 2016a. Disponível em: <http://www.in.gov.br/materia/-/asset_publisher/Kujrw0TZC2Mb/ content/id/21772550/do1-2016-07-20portaria-n-213-de-19-de-julho-de-2016-21772471>. Acesso em: 20 jan. 2020.

Ministério da Justiça e Cidadania. Municípios de fronteira: mobilidade transfronteiriça, migração, vulnerabilidades e inserção laboral. Brasília: MJ, 2016b. (Relatório de Pesquisa).

. Ministério da Integraçáo Nacional. Portaria no 1.080 de 24 de abril de 2019. Inclui o Município no Anexo da Portaria n. 213, de 19 de julho de 2016, que estabelece o conceito de "cidades-gêmeas" nacionais, os critérios adotados para essa definição e lista todas as cidades brasileiras por Estado que se enquadram nesta condição. Diário Oficial da Uniáo, Brasília, 29 abr. 2019. Disponível em: <https://www.in.gov.br/web/dou/-/portaria-n\%C2\%BA-1.080-de24-de-abril-de-2019-85673267>. Acesso em: 20 set. 2020. 
CARDOSO, N. A.; MOURA, R. Regiôes de fronteira e fluxos migratórios: o caso do Paraná. In: PENHA, B.; DESIDERÁ NETO, W. A.; MORAES, R. F. (Org.). O Mercosul e as regióes de fronteira. Rio de Janeiro: Ipea, 2017. p. 53-100.

DESCHAMPS, M.; DELGADO, P.; MOURA, R. Mobilidade pendular na faixa de fronteira brasileira: particularidades dos arranjos transfronteiriços. In: PÊGO, B.; MOURA, R. (Org.). Fronteiras do Brasil: uma avaliação de política pública. Rio de Janeiro: Ipea, 2018. v. 1. p. 293-321.

EGLER, C. A. G. Referenciais básicos para uma metodologia de identificação do sistema urbano da América do Sul. In: FURTADO, B.; PÊGO, B. (Coord.). Rede urbana e integraçáo produtiva no Brasil e na América do Sul. Brasília: Ipea; Cepal; Ipardes, 2015. (Relatório de Pesquisa).

IBGE - INSTITUTO BRASILEIRO DE GEOGRAFIA E ESTATÍSTICA. Arranjos populacionais e concentraçóes urbanas no Brasil. 2. ed. Rio de Janeiro: IBGE, 2016.

Regióes de Influência das Cidades 2018. Rio de Janeiro: IBGE, 2020. Disponível em: <https://biblioteca.ibge.gov.br/visualizacao/livros/liv101728.pdf>. Acesso em: 30 jul. 2020.

MOURA, R.; OLIVEIRA, S. Referências sobre a faixa de fronteira e os arranjos transfronteiriços do Brasil. In: PÊGO, B.; MOURA, R. (Org.). Fronteiras do Brasil: uma avaliaçâo de política pública. Rio de Janeiro: Ipea, 2018. v. 1. p. 243-292.

PÊGO, B. et al. Fronteiras do Brasil: referências para a formulação de políticas públicas para as fronteiras brasileiras. Brasília: Ipea; MDR, 2021. v. 6.

PÊGO, B.; MOURA, R. (Org.). Fronteiras do Brasil: uma avaliação de política pública. Rio de Janeiro: Ipea, 2018. v. 1. 
